\title{
POTENTIATION OF ZINC STRESS CAUSED BY PARASITIC INFECTION OF SNAILS
}

\author{
Daniel J. GUTH ${ }^{1}$, Harvey D. BLANKESPOOR ${ }^{2}$, \& John CAIRNS, Jr. ${ }^{3}$ \\ ${ }^{1}$ Department of Biology, University of Michigan-Flint, Flint, Michigan 48503 \\ ${ }^{2}$ Museum of Zoology, University of Michigan, Ann Arbor, Michigan 48 ro9 \\ ${ }^{3}$ Biology Department and Center for Environmental Studies, Virginia Polytechnic Institute and State University, Blacks- \\ burg, Virginia 2406 I
}

Received January 26, I977

Keywords: pollution, parasites, zinc, bioassay

\begin{abstract}
The purpose of this experiment was to determine the effects of parasitism (Schistosomatium douthitti Price and Trichobilhar$z i a$ sp.) on the tolerance of snails Lymnaea stagnalis (L.) to acutely lethal concentrations of zinc. Significant reduction in tolerance occurred for snails with patent infections at 24 and $75 \mathrm{ppm}$ of $\mathrm{Zn}^{++}$. At two selected prepatent levels of parasite development, significant differences occurred at the higher concentration only.
\end{abstract}

\section{Introduction}

Although a substantial percentage of organisms in natural systems are parasitized, there is very little literature on the relationship between a parasitic infection and resistance to pollutional stress caused by toxicants. For example, the influence of parasitism on the sensitivity to a wide variety of toxic chemicals is not substantively discussed in Water Quality Criteria of $1972^{1}$. Intuitively, one feels that a parasitic infection detrimental to the host would substantially weaken the host's resistance to various toxicants or other pollutional stresses. However, the degree or stage of infection necessary to moderate the response and the extent to which the response is altered are not well documented. The congregation of fish near municipal sewage outfalls, heated wastewater discharges from power plants, and a variety of other point source dis-

Dr. W. Junk b.v. Publishers - The Hague, The Netherlands charges might well increase the opportunity for parasite transfer from an infected individual to a number of other individuals in the population. At the same time, the tendency to aggregate in the proximity of an outfall also places the organisms in a higher concentration of various toxicants, such as chlorine or heavy metals, than if they were more widely dispersed in the river or other receiving water body. This is, of course, mostly true for fish since they are highly mobile and able to change their distributional patterns readily. The purpose of this study was to provide some information on some of these questions for one toxicant.

This experiment was designed to determine the tolerance of parasitized Lymnaea stagnalis (L.) when chemically stressed with zinc. Snails were parsitized with two species of digenetic trematodes, Schistosomatium douthitti Price and Trichobilharzia sp. The former are found as adults in voles and muskrats; the latter is a parasite in ducks. Snails with patent infections of both trematodes as well as snails with I2- and 23-day-old infections of $S$. douthitti were tested.

The importance of parasitic infection in reducing the tolerance to chemicals has rarely been considered either in laboratory or in field bioassays. Because parasites are present in all groups of animals, it seems important to determine the extent to which infection reduces tolerance to chemical stress.

Some studies have been undertaken to determine the synergistic effects when two chemicals or a chemical and a physical stress are applied, but little has been done to 
relate a physical or chemical stress to a natural biological condition such as parasitism. Parasitism has recently been cited in bioassay literature ${ }^{2}{ }^{3}$ in considering methods for decreasing variability of results. There are several reasons why snails should be used to test the effects of parasitism. They are usually abundant in lakes and rivers; they are of ten unable to move quickly out of an area being stressed. Perhaps more important is the role that molluscs play as the obligatory intermediate hosts for digenetic trematodes.

\section{Materials and methods}

Lymnaea stagnalis was a useful test organism for these particular bioassays for several reasons: (I) availability of large numbers of naturally infected snails, and (2) adequate numbers of infected and uninfected snails in the laboratory. Snails were kept in 20-gallon aquaria filled with lake water and were fed each day until one day prior to testing. Food consisted of fresh lettuce supplemented by crushed oyster shell serving as a source of calcium.

The snails, ranging in size from $19-35 \mathrm{~mm}$, came from several sources. Those used for the preliminary LC50 determination were collected at random from a ditch at Alanson, Michigan and may have included both infected and uninfected specimens. They were chosen in this way because the $\mathrm{LC} 50$ test was necessary to provide a rough estimate of their acute exposure tolerance limits. Those used for the final tests included lab-reared and experimentally and naturally infected snails. Naturally infected snails were collected from Alanson at various times between Io July 1976 and 3 August 1976 and included those infected with both species of trematodes. Cercariae of Schistosomatium douthitti are shed at night; the candidate snails are placed under flourescent light for 24 hours, then individually isolated in vials and exposed to darkness for I hour. On the other hand, Trichobilharzia sp. emerge during the day so the process is reversed; snails are kept in darkness for 24 hours and then placed in the light for I hour.

Laboratory reared snails from the Medical Malacology Unit, Museum of Zoology, University of Michigan stocks were exposed to miracidia of $S$. douthitti obtained from eggs by grinding the liver of an infected hamster. Each snail was placed in a vial and exposed to a constant number of miracidia. Experimental infections using laboratory snails only involved $S$. douthitti. Two batches of snails, differing in size, were infected. The larger-sized snails were used in tests at 12 days post-infection on 16 July 1976 . The smaller-sized snails were used in tests at 23 days post-infection. Except for the 23-days post-infection snails, all tests involved snails of comparable size. Another group of snails were laboratory-reared and used as the controls.

In these tests static bioassay methods were used as described by Sprague $^{3}$. In all cases the tests were conducted at room temperature. The dilution water was taken from the surface of Douglas Lake and was used also for maintaining the snails. With the exception of the preliminary $\mathrm{LC}_{50}$ determination, all water used in tests was aerated. Tests were made in glass containers, detergent cleaned, and rinsed in lake water; each aquarium contained Io snails in 2 liters of solution. All snails were acclimated to laboratory conditions for at least 3 days prior to testing. Dilutions were prepared from a stock solution according to Standard Methods ${ }^{4}$ to provide graded series of concentrations for the LCIO test and to obtain concentrations for the final tests. Chemical determinations were made with a Hach kit before and after each test to include D.O., $\mathrm{pH}$, and hardness, temperatures were monitored to maintain constant conditions. The criterion for death of the snails was their failure to respond when the sensitive anterior end of the foot was probed.

The preliminary dose-effect test was run using concentrations from 0.1 to $100 \mathrm{ppm} \mathrm{Zn}^{++}$; the results were plotted on log-probit graph paper to estimate the $\mathrm{LC}_{5} \mathrm{O}$ after Sprague $^{3}$. After examining the LC50 values for 6, 14, 24 and 48 hours, two concentrations were selected arbitrarily for use in the final tests to provide an acutely lethal response in about 6 to 2 hours. These concentrations were $24 \mathrm{ppm}$ and $75 \mathrm{ppm} \mathrm{Zn}^{+4}$. A summary of the experimental design is given in Table $I$.

The tests consisted of subjecting infected snails and uninfected snails (control) to an acutely lethal concentration of $\mathrm{Zn}^{++}$. Observations were made at half-hour intervals until $100 \%$ mortality was attained. These data for each test at each concentration were compared using the Wilcoxon rank sum test ${ }^{5}$ including the correction for large sample size for the 12- and 23-day-old infection tests. Four such tests were run including $S$. douthitti infections of 12 days, 23 days patent; and patent infections of Triof 12 days, 23 days, patent; and patent infections of Tri-

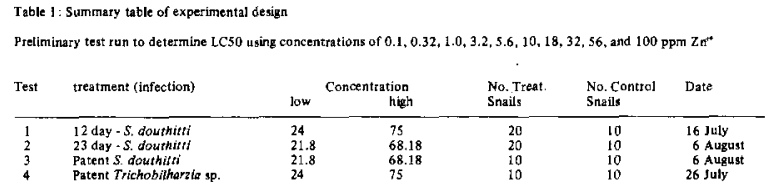


chobilharzia sp. The tests with I2- and 23-day-old infections each had two treatment groups run in parallel at each concentration because enough snails were available. Each test was a comparison of survival of infected snails to control snails at a given concentration of toxicant. Water in these tests were aerated continuously; snails were not fed during the course of the test. Tests were run at ambient temperature and never varied over a range greater than $2^{\circ} \mathrm{C}$. The length of each snails used was recorded for each group, and the mean length recorded to account for any inconsistency due to size differences. In each case, lengths of randomly selected snails to be placed in each concentration were recorded for the group such as Test 3 controls.

The life cycles of both species of schistosomes are very similar. Adults of $S$. douthitti and Trichobilharzia sp. occur in the hepatic portal and mesenteric veins of rodents (voles and muskrats) and birds, respectively. In both species, eggs are passed out of the host with the feces. Miracidia hatch when these eggs are diluted with water. If the miracidia come in contact with a suitable snail, they burrow through its tegument and elongate to form mother sporocysts. At approximately Io days, mother sporocysts begin producing daughter sporocysts which migrate to the digestive gland of the snail. These continue to accumulate and develop in the snail until much of the snail's biomass is comprised of sporocyst. $S$. douthitti cercariae, produced by the second generation of sporocysts, emerge from the snail six weeks after the initial exposure. The intramolluscan development of Trichobilharzia sp. is usually shorter, reaching patency after $4-5$ weeks. It is safe to assume that infected snails become increasingly more stressed as the infection develops. Therefore, the 12-, 23-day-old, and patent infections represent levels of parasitism that probably show different tolerance to zinc.

Zinc was used as the toxicant bacause it is common in industrial wastes. There is also a substantial body of literature on its effects on other organisms against which these data can be compared.

\section{Results}

The LC50 values determined from the preliminary test along with confidence limits are presented in Table 2. Confidence limits were calculated using the formula given by Litchfield and Wilcoxon ${ }^{7}$ and are shown in Table 3. These confidence limits are fairly wide bacause the
Table 2: LC50 values and confidence limits

$\begin{array}{cccc}\frac{\text { Time }}{6 \mathrm{hrs} .} & \text { 95\% confidence } & & \text { LC50 } \\ 14 \mathrm{hrs} . & 8.33-12.0 & & 64 \mathrm{ppm} \\ 24 \mathrm{hrs} . & 5.58-8.04 & & 10 \mathrm{ppm} \\ 48 \mathrm{hrs} . & 4.31-7.28 & & 6.7 \mathrm{ppm} \\ & & & 5.6 \mathrm{ppm}\end{array}$

LC50 values are not bracketed by other points because snails in the test died in a short interval, reducing the statistical reliability of the test. A probable factor causing this was that water in the test tanks was not aerated during the $\mathrm{LC}_{5} \mathrm{O}$ test. While the dissolved oxygen concentration was at saturated levels at the beginning of the test, the final samples showed oxygen concentration was reduced to 5 $\mathrm{ppm}$. Such a change has been shown to markedly increase the toxicity of zinc ${ }^{1}$ and may have caused the rapid dieoffs. However, the variability was tolerable at this experimental stage because the test served its primary purpose in providing a rough estimate of the LC5O.

Results using the Wilcoxon rank sum test are presented in Table 4. Its design involves continuous data and observations taken at short enough intervals to approximate continuity. The test determines the presence of a treatment effect which shifts relative to the control curve and tests the null hypothesis of no shift in the line; this shift may or may not include a shift in the slope of the line. The test includes a large sample approximation used for tests $I$ and 2 as given in Table 3 .

Tests 3 and 4 both include snails with patent infections which cause the most damage to the host. Both tests show significant differences in treatment and control indicating

Table 3: Large sample approximation from Hollander and Wolfe

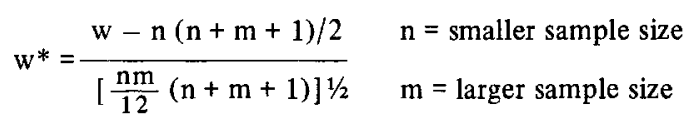

95\% confidence intervals for LC50 from Litchfield and Wilcoxon

Confidence limits $=$ LC50/fLC50 to LC50 x fLC50

$\mathrm{fLC50}=\mathrm{S} 2.77 / \sqrt{\mathrm{N}^{\prime}} \quad \mathrm{N}^{\prime}=$ number of organisms with mortality between $76 \%$ and $89 \%$

$\mathrm{S}=$ slope $=\frac{\mathrm{LC}_{84} / \mathrm{LC} 50+\mathrm{LC} 50 / \mathrm{LC} 16}{2}$

$\mathrm{w}^{*}=$ statistic given by the large sample approximation

$\mathrm{w}=$ rank sum of smaller sample size or smaller sum if equal sample size 


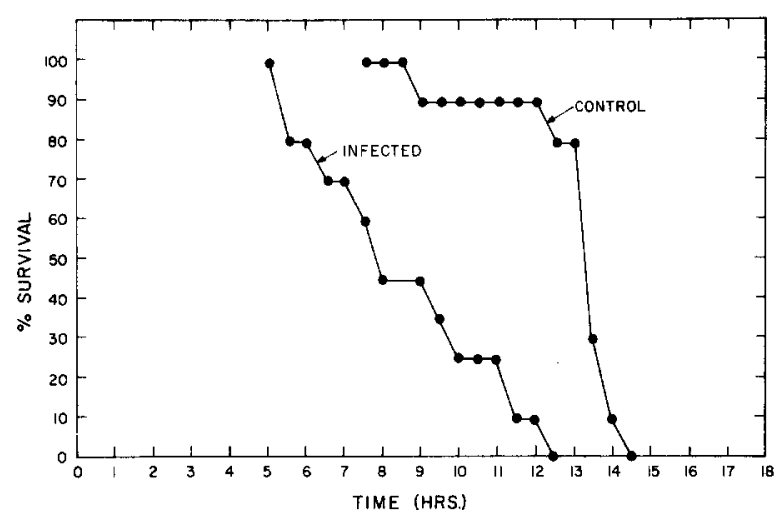

Fig. I. Mortality curve of Lymnaea stagnalis with I2-day-old infection of Schistosomatium douthitti using $24 \mathrm{ppm} \mathrm{Zn}^{++}$(Test I).

that this progression of the infection has drastic effects on the tolerance of the host to stress (Figs. 2 and 3). Results for Trichobilharzia sp. showed much more pronounced differences as evidenced both graphically and by the difference in the $\alpha w$ values of the two. Possibly, Trichobilharzia sp. has a much greater effect on the host than does S. douthitti.

\section{Conclusions}

The statistical analyses for Tests I (Fig. I) and 2 indicate that, in both cases, the infection caused a difference from the controls only at the higher concentration of the toxicant. There was a definite reduction in the tolerance of $L$. stagnalis to acutely lethal concentrations of zinc due to further progression of the infection although the difference was less pronounced in snails with younger infections.

Chemical parameters were rather constant throughout the tests (ranges: temperature $20-23^{\circ} \mathrm{C}$; hardness $154-$ I7I ppm; $\mathrm{pH}$ 7.5-8.5; dissolved oxygen concentration 9 ppm except for the LC50 test which went to a final concentration of $5 \mathrm{ppm}$ ). The fact that the dissolved oxygen was kept at saturation by aeration is important because decrease of oxygen concentration increases the toxicity of zinc.

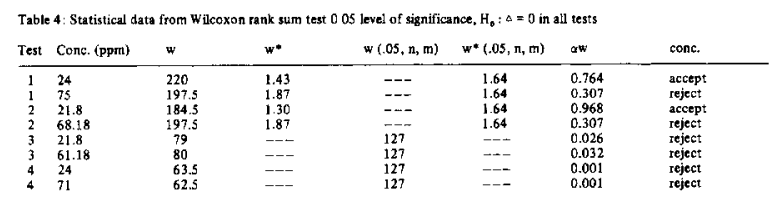

$w^{*}=$ statistic given by the large sample approximation

-

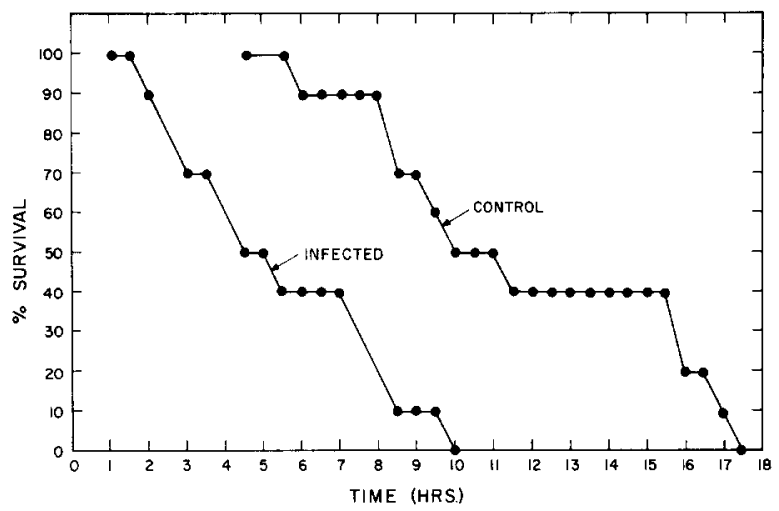

Fig. 2. Mortality curve of Lymnaea stagnalis with patent infection of Trichobilharzia sp. using $24 \mathrm{ppm} \mathrm{Zn}^{++}$(Test 4).

It is unfortunate that the level of infection is difficult to determine precisely for large numbers of test specimens. The exposure method has been shown to be about $65 \%$ effective due to the resistance of some snails to infection. There is also variability in the number of miracidia which penetrate each host.

This experiment indicates that parasitism by larval stages of Schistosomatium douthitti and Trichobilharzia $\mathrm{sp}$. in Lymnaea stagnalis affected the tolerance of the snail to acutely lethal doses of zinc. The consequences of parasitism were much more pronounced in Trichobilharzia sp. and were more pronounced in late stages of infection than in the two early stages of infection studied. The differences in these two stages of development of the parasite were significant at the higher toxicant concentrations but not demonstrably different at the lower concentrations.

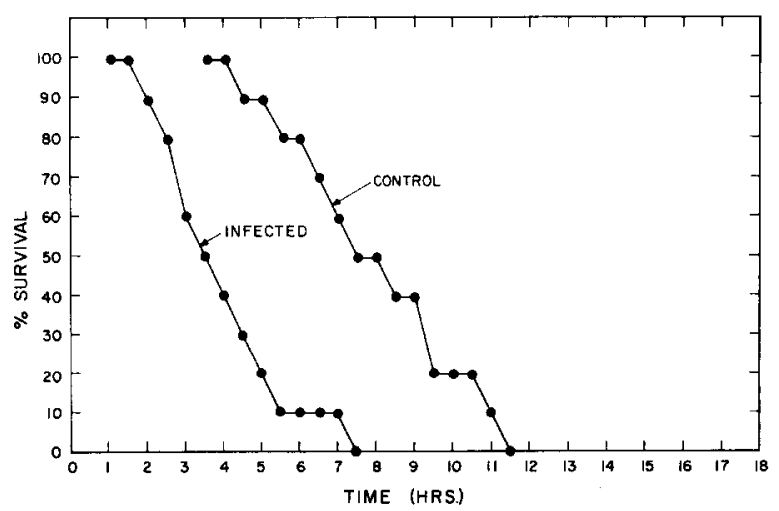

Fig. 3. Mortality curve of Lymnaea stagnalis with patent infec-

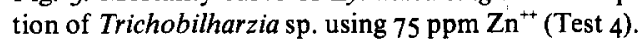




\section{Acknowledgments}

This study was carried out entirely at the University of Michigan Biological Station, Pellston, Michigan. We are indebted to Matthew J. McGinniss for help in setting up the experiments and to Dr. Henry van der Schalie for reading a rough draft of this manuscript.

\section{References}

I. Environmental Studies Board. I972. 'Water Quality Criteria 1972.' National Academy of Sciences, Washington, D. C.

2. Smith, L. L., Jr., Auerbach, S. 1., Cairns, J., Jr., Mount, D. I., Rohlich, G. A., Sprague, J. B., Klein, W. L., I973. 'ORSANCO 24-Hour Bioassay.' Ohio River Valley Water Sanitation Commission, Cincinnati.

3. Sprague, J. B. 1973. 'The ABC's of Pollutant Bioassay Using Fish.' American Society for Testing and Materials. Spec. Publ. No. 528,6 .

4. American Public Health Association. 1975. 'Standard Methods for the Examination of Water and Wastewater.' Washington, D. C.

5. Hollander, Myles \& Wolfe, D. A. I 973. 'Nonparametric Statistical Methods.' John Wiley and Sons, New York.

6. Olsen, O. W. I974. 'Animal Parasites, Their Life Cycles and Ecology.' 3rd ed. University Park Press, Baltimore.

7. Litchfield, J. T. \& Wilcoxon, F. 1949. 'A Simplified Method of Evaluating Dose-Effect Experiments.' J. Pharmacol. Exp. Ther., 96, 99. 